\title{
Research Supplements for Underrepresented Minorities, Notice
}

National Cancer Institute

\section{Source}

National Cancer Institute. Research Supplements for Underrepresented Minorities,

Notice. NCI Thesaurus. Code C19007.

The NIH is emphasizing the use of administrative supplements to attract

underrepresented minorities into biomedical and behavioral research. Funds are available for administrative supplements to existing grants for the support and recruitment of underrepresented minority investig ators and students. The aim of these supplements is to attract and encourage minority individuals to enter and pursue biomedical and behavioral research careers in areas within the missions of all the awarding components of the NIH by providing supplemental funds to certain ongoing research grants. (from Research Supplements For Underrepresented Minorities, NIH Guide, Volume 25, Number 3, February 9, 1996) 